\title{
Cabergoline use for cushing's disease during pregnancy: Mini review
}

\author{
Mussa Almalki ${ }^{1,2 *}$ \\ ${ }^{1}$ Obesity, Endocrine, and Metabolism Center, King Fahad Medical City, Riyadh, Saudi Arabia \\ ${ }^{2}$ King Saud bin Abdulaziz University for Health Science, College of Medicine, King Fahad Medical City, Riyadh, Saudi Arabia
}

\begin{abstract}
Cushing disease (CD) rarely occurs during pregnancy and is associated with significant maternal and fetal comorbidity. The usual first-line treatment is surgery, and when surgery, is not feasible, medical therapy is usually considered. However, treatment of CD during pregnancy has consisted of conservative management without specific treatment. Cabergoline, is the drug of choice for treating hyperprolactinemia, is also found to be effective in reducing hypercortisolism in CD and used off- label for treating CD during pregnancy. Data concerning the safety of cabergoline use in pregnancy did not show any potential adverse effect of the drug on pregnancy outcome.
\end{abstract}

\section{Introduction}

Pregnancy rarely occurs in a patient with Cushing's syndrome (CS), due to the effect of hypercortisolism on the reproductive axis [13]. To date, approximately 263 cases of Cushing's syndrome have been reported in the literature [4].

The etiology of CS diagnosed during pregnancy is different from the general population as adrenal adenoma account for the most frequent cause of reported cases and only about $40 \%$ caused by ACTH- secreting pituitary adenoma [5]. However, the occurrence of pregnancy often is associated with significant maternal and fetal morbidity. Maternal complications include hypertension, preeclampsia, impaired glucose tolerance, diabetes and premature labor [5]. The fetus may experience increased risk for prematurity, intrauterine growth retardation, miscarriage, and stillbirths [5].

The treatment aims are to reduce maternal and fetal risks and poor outcomes of CS in pregnancy. Although well-controlled hypercortisolism has not been shown to decrease the incidence of premature births or rates of intrauterine growth restriction, it does appear to reduce stillbirth [6,7]. Treatment of CS in pregnancy has consisted of conservative management, medical therapy as well as surgery. Drug therapy is now the preferred second-line option for patients with CS after surgery. Various drugs are now available, including dopamine agonists (DAs), metyrapone, and ketoconazole. This review focuses on medical therapy with cabergoline.

\section{Rationale for the use of cabergoline in cushing disease}

The dopamine action is mediated by five specific receptors subtypes (D1-D5) [8]. The different dopamine receptor (DR) subtypes have different distributions and different roles in the various organs [8].

The D2 receptor is the predominant DR subtype in pituitary gland $[9,10]$. The expression of dopamine binding sites on corticotroph pituitary adenomas was demonstrated by Pivonello, et al. [11]. DA was hypothesized to induce a suppression of ACTH secretion and inhibition of cell growth in corticotroph pituitary adenoma, acting through DRs expressed in ACTH-secreting pituitary tumors [11]. Bromocriptine was the first DA to be used in a treatment of corticotroph pituitary tumors with variable result $[12,13]$.

Cabergoline was reported reduces cortisol secretion in $60 \%$, but the normalization of cortisol secretion in only $40 \%$ of patients [11]. Being more effective and tolerated than bromocriptine, it is potentially useful for the treatment of CD [11].

\section{Responsiveness to treatment with cabergoline}

Ideally, CD should be appropriately treated surgically before pregnancy, because of the potential untoward effects on maternal and fetal health.

The optimal approach to women with active $\mathrm{CD}$ who become pregnant is controversial.

In patients with $\mathrm{CD}$ during pregnancy, $39.9 \%$ received treatment during gestation. Of these, $11.3 \%$ women only received medical treatment. DA have been successfully used for CD during pregnancy in minority of patients with no major adverse effects noted [4].

Furthermore, cabergoline doses for $\mathrm{CD}$ in pregnancies varied from 1-7 mg/wk (with a median dose of $3.5 \mathrm{mg} / \mathrm{wk}$ ) as compared to lower doses of cabergoline $(0.125-4.0 \mathrm{mg} / \mathrm{wk})$ used to treat hyperprolactinemia in pregnant patients $[14,15]$.

Although cabergoline is an FDA pregnancy category B drug, there are no clinical trials has as yet tested the safety of high-dose cabergoline for Cushing disease in pregnancy [16].

Woo, et al. reported a case of CD managed with high-dose cabergoline throughout pregnancy up to $10 \mathrm{mg}$ per week with favorable maternal and fetal outcome [16].

Correspondence to: Mussa Hussain Almalki, Obesity, Endocrine, and Metabolism Center, King Fahad Medical City, Riyadh, Kingdom of Saudi Arabia, Tel: 00966-1-2889999, Ext. 4042; Fax: 00966-1-2889999 Ext.8022; E-mail: m2malki@yahoo.com

Key words: cushing disease, cabergoline, pregnancy

Received: March 02, 2017; Accepted: March 13, 2017; Published: March 15, 2017 
Other reports in a patient with pregnancy-induced CS, use of a combination of ketoconazole with cabergoline dose ranged only from $0.12-0.25 \mathrm{mg}$, with no adverse effect, were noted on pregnancy outcome [17].

Furthermore, a recent case report described a woman with CD who underwent a non-curative pituitary surgery and who conceived spontaneously four months after initiating cabergoline and was maintained at the dose of $2 \mathrm{mg} /$ week, throughout gestation with complete clinical and biochemical remission and no maternal or fetal complications were evident [18].

Overall, normalization of UFC excretion could be obtained in two patients who submitted to cabergoline alone and in one undergoing the combination of cabergoline with ketoconazole.

\section{Safety aspects of using Cabergoline during pregnancy}

Experience with the use of cabergoline during pregnancy is limited as compared to bromocriptine. Most data on the safety of the use of cabergoline during pregnancies in women treated with cabergoline from women with prolactinomas $[19,20]$.

Pregnancies with exposure of the fetus during the first few weeks of pregnancy have been reported in over 900 prolactinoma cases has not demonstrated an increased risk of spontaneous abortion, premature delivery, or multiple births [19].

Outcome data with regards to malformations were available for 822 cases with a finding of only $2.4 \%$ major malformations [21-23].

Use of cabergoline throughout gestation in 15 women with prolactinoma, with no abnormalities, noted [24].

A follow-up study up to 12 years of 223 children whose mothers took cabergoline in the first few weeks of gestation showed no abnormalities in their physical or mental development $[25,26]$.

Cabergoline was in CD during pregnancy with higher dose well tolerated, and none of the published cases had a side effect or interrupt the treatment. Moreover, none of the patients experienced any significant cardiac symptom or sign [16-18].

\section{Conclusion}

The data collected from these cases suggest that Cabergoline therapy during gestation may be both safe and effective in the management of active $\mathrm{CD}$ during gestation. This limited data provides some preliminary evidence that cabergoline therapy if needed for active $\mathrm{CD}$ even with higher doses, may be continued during pregnancy without unwanted concerns regarding fetal growth and development. However, further studies are needed to determine the role of cabergoline use and safety in pregnant women with $\mathrm{CD}$.

\section{Declaration of interest}

The author declares that they have no conflict of interest.

\section{Funding}

This study was not funded.

\section{References}

1. Laway BA, Mir SA (2013) Pregnancy and pituitary disorders: Challenges in diagnosis and management. Indian J Endocrinol Metab 17: 996-1004.[Crossref]

2. Abdelmannan D, Aron DC (2011) Adrenal disorders in pregnancy. Endocrinol Metab Clin North Am 40: 779-794.[Crossref]

3. Vilar L, Freitas Mda C, Lima LH, Lyra R, Kater CE (2007) Cushing's syndrome in pregnancy: an overview. Arq Bras Endocrinol Metabol 51: 1293-1302.[Crossref]

4. Caimari F, Valassi E, Garbayo P (2017) Cushing's syndrome and pregnancy outcomes: a systematic review of published cases. Endocrine 55: 555-563.[Crossref]
5. Lindsay JR, Nieman LK (2005) The hypothalamic-pituitary-adrenal axis in pregnancy: challenges in disease detection and treatment. Endocr Rev 26: 775-799.

6. Pinette MG, Pan YQ, Oppenheim D, Pinette SG, Blackstone J (1994) Bilateral inferior petrosal sinus corticotropin sampling with corticotropin-releasing hor- mone stimulation in a pregnant patient with Cushing's syndrome. Am J Obstet Gynecol 171: 563-564

7. Cabezón C, Bruno OD, Cohen M, García S, Gutman RA (1999) Twin pregnancy in a patient with Cushing's disease. Fertil Steril 72: 371-372.[Crossref]

8. Missale C, Nash SR, Robinson SW, Jaber M, Caron MG (1998) Dopamine receptors from structure to function. Physiol Rev 78: 189-225.[Crossref]

9. Caron MG, Beaulieu M, Raymond V, Gagné B, Drouin J, et al. (1978) Dopaminergic receptors in the anterior pituitary gland. Correlation of $[3 \mathrm{H}]$ dihydroergocryptine binding with the dopaminergic control of prolactin release. J Biol Chem 253: 22442253.[Crossref]

10. Munemura M, Cote TE, Tsuruta K, Eskay RL, Kebabian JW (1980) The do-pamine receptor in the intermediate lobe of the rat anterior pituitary gland: pharmacological characterization. Endocrinology 106:1676-1683.

11. Rosario pivonello, Diego ferone, Wouter w. de herder, Johan m. kros, et al. (2004) Dopamine receptor expression and function in corticotroph pituitary tumors. J clinendocrinolmetab 89: 2452-2462.

12. Shimon I, Melmed S (1998) Management of pituitary tumors. Ann Intern Med 129 472-483.[Crossref]

13. Miller JW, Crapo L (1993) The medical treatment of Cushing's syndrome. Endocr Rev 14: 443-458.[Crossref]

14. Robert E, Musatti L, Piscitelli G, Ferrari CI (1996) Pregnancy outcome after treatment with the ergot derivative, cabergoline. Reprod Toxicol 10: 333-337.

15. Pivonello R, De Martino MC, Cappabianca P, De Leo M, Faggiano A, et al. (2009) The medical treatment of Cushing's disease: effectiveness of chronic treatment with the dopamine agonist cabergoline in patients unsuccessfully treated by surgery. $J$ Clin Endocrinol Metab 94: 223-230.

16. Irene W, Robert M (2013) Cabergoline Therapy for Cushing Disease Throughout Pregnancy. Obstet Gynecol 122: 485-487.

17. Berwaerts J, Verhelst J, Mahler C, Abs R (1999) Cushing's syndrome in pregnancy treated by ketoconazole: case report and review of the literature. Gynecol Endocrinol 13: 175-182.[Crossref]

18. Nakhleh A, Saiegh L, Reut M, Ahmad MS, Pearl IW, et al. (2016) Cabergoline treatment for recurrent Cushing's disease during pregnancy. Hormones (Athens) 15: 453-458.[Crossref]

19. Molitch ME (2015) Endocrinology in pregnancy: management of the pregnant patient with a prolactinoma. Eur J Endocrinol 172: R205-213.[Crossref]

20. Ricci E, Parazzini F, Motta T, Ferrari CI, Colao A, et al. (2002) Pregnancy outcome after cabergoline treatment in early weeks of gestation. Reprod Toxicol 16: 791-793.

21. Molitch ME (2011) Prolactinoma in pregnancy. Best Pract Res Clin Endocrinol Metab 25: 885-896.[Crossref]

22. Auriemma RS, Perone Y, Di Sarno A, Grasso LF, Guerra E, et al. (2013) Results of a single-center 10-year observational survey study on recurrence of hyperprolactinemia after pregnancy and lactation. JCEM 98: 372-379.

23. Domingue ME, Devuyst F, Alexopoulou O, Corvilain B, Maiter D (2014) Outcome of prolactinoma after pregnancy and lactation: a study on 73 patients. Clinical Endocrinology 80: 642-648.

24. Glezer A, Bronstein MD (2014) Prolactinomas, cabergoline, and pregnancy. Endocrine 47: 64-69.[Crossref]

25. Ono M, Miki N, Amano K, Kawamata T, Seki T, et al. (2010) High-dose cabergoline therapy for hyperprolactinemic infertility in women with micro- and macroprolactinomas. JCEM 95: 2672-2679.

26. Lebbe M, Hubinont C, Bernard P,Maiter D (2010) Outcome of 100 pregnancies initiated under treatment with cabergoline in hyper-prolactinaemic women. Clinical Endocrinology 73: 236-242.

Copyright: (C2017 Almalki MH. This is an open-access article distributed under the terms of the Creative Commons Attribution License, which permits unrestricted use, distribution, and reproduction in any medium, provided the original author and source are credited. 